\title{
PERSPECTIVE OPEN \\ Primary care implications of the British Thoracic Society Guidelines for bronchiectasis in adults 2019
}

\author{
Kevin Gruffydd-Jones ${ }^{1}$, Duncan Keeley ${ }^{2}$, Vikki Knowles ${ }^{3}$, Ximena Recabarren ${ }^{4}$, Alex Woodward ${ }^{5}$, Anita L. Sullivan ${ }^{6}$, \\ Michael R. Loebinger ${ }^{7}$, Karen Payne ${ }^{8}$, Alex Harvey ${ }^{9}$, Lizzie Grillo ${ }^{10}$, Sally A. Welham ${ }^{11}$ and Adam T. Hill ${ }^{12}$
}

The British Thoracic Society (BTS) Guidelines for Bronchiectasis in adults were published in January 2019, and comprise recommendations for treatment from primary to tertiary care. Here, we outline the practical implications of these guidelines for primary care practitioners. A diagnosis of bronchiectasis should be considered when a patient presents with a recurrent or persistent ( $>8$ weeks) productive cough. A definitive diagnosis is made by using thin-section chest computed tomography (CT). Once diagnosed, patients should be initially assessed by a specialist respiratory team and a shared management plan formulated with the patient, the specialist and primary care teams. The cornerstone of primary care management is physiotherapy to improve airway sputum clearance and maximise exercise capacity, with prompt treatment of acute exacerbations with antibiotics.

npj Primary Care Respiratory Medicine (2019)29:24 ; https://doi.org/10.1038/s41533-019-0136-8

\section{INTRODUCTION}

Bronchiectasis is a condition where patients have symptoms of persistent or recurrent bronchial sepsis related to irreversibly damaged and dilated bronchi. ${ }^{1}$ The incidence and prevalence of bronchiectasis is rising. Using the Clinical Practice Research Datalink (CPRD) in the United Kingdom, patients 18 and over with a Read code of Bronchiectasis were identified, and the point prevalence in February each year from 2004 to 2013 was measured. This showed that the point prevalence of coded bronchiectasis rose from 351 to 566 per 100,000 in women and from 301 to 486 per 100,000 in males between 2004 and 2013. ${ }^{2}$ A retrospective study using healthcare data from the United States showed a rise in prevalence of $8 \%$ between 2001 and 2012, but with a point prevalence of $139 / 100,000 .^{3}$ The British Thoracic Society (BTS) Guideline for non-cystic fibrosis (non-CF) bronchiectasis was published in $2010^{4}$ and included children. The BTS commissioned an update to the guidelines in 2013 to take into account any new evidence. The new BTS Guideline covers bronchiectasis in adults and provides recommendations and good practice points based on an updated evidence review. ${ }^{1}$

Systematic electronic database searches of relevant literature were carried out in June 2014 and June 2016, identifying relevant papers published since the previous guideline. In total, 1799 such papers were identified and reviewed by pairs of Guideline Committee members. Appraisal of the evidence was carried out based on Scottish Intercollegiate Guidelines Network (SIGN) methodology, as set out in the BTS Guideline Production Manual. ${ }^{5}$ The reliability of the evidence in each individual study was graded, using the SIGN critical appraisal checklists and levels of evidence assigned to evidence statements, according to the levels of evidence in Table 1., ${ }^{5,6}$ Recommendations made by the Guideline
Committee were formulated based on the evidence statements and graded according to the SIGN grading system (Table 2). ${ }^{6}$

The composition of the Guideline Committee and the subsequent guideline recommendations were biased towards secondary care. One member of the Guideline Committee (KGJlead author of this paper) was from primary care. This paper acknowledges this and with five primary care authors aims to look at the relevance of the guidelines for primary care.

\section{INITIAL PRESENTATION OF BRONCHIECTASIS}

A diagnosis of bronchiectasis should be suspected when a patient presents with a recurrent or persistent ( $>8$ weeks) cough, with production of purulent or mucopurulent sputum, particularly with the relevant associated risk factors, such as COPD. This diagnosis is particularly likely if the patient has a history of two or more COPD exacerbations per year and a previous positive sputum sample for Pseudomonas aeruginosa whilst stable (i.e. not during an exacerbation). ${ }^{1}$

A meta-analysis of six observational studies of 881 patients, mainly based on secondary care, found that the prevalence of bronchiectasis was $54.3 \%$ in patients with COPD. ${ }^{7}$ One study conducted in 110 patients from 29 UK general practices showed that the prevalence of bronchiectasis was $29 \%$ in patients with COPD. ${ }^{8}$ Patients with bronchiectasis and COPD had a lower $\mathrm{FEV}_{1-}$ weighted mean difference (WMD)-8\%, more frequent exacerbations (WMD 1.54 times more in the previous year) and 7.33 times more likely to have persistent sputum pathogens, especially $P$. aeruginosa than COPD patients without bronchiectasis. ${ }^{7}$

In addition to coincident presentation with COPD, a diagnosis of bronchiectasis should be suspected in patients presenting with

\footnotetext{
${ }^{1}$ Box Surgery, Wiltshire, UK; ${ }^{2}$ Thame Health Centre, Thame, UK; ${ }^{3}$ Virgin Care, Farnham Hospital, Farnham, UK; ${ }^{4}$ Respiratory Department, Royal Infirmary of Edinburgh, Edinburgh, UK; ${ }^{5}$ Leicestershire Partnership NHS Trust, Leicester, UK; ${ }^{6}$ Department of Respiratory Medicine, University Hospitals Birmingham NHS Foundation Trust (Queen Elizabeth Hospital), Birmingham, UK; ${ }^{7}$ Host Defence Unit, Department of Respiratory Medicine, Royal Brompton Hospital and Harefield NHS Foundation Trust, London, UK; ${ }^{8}$ Glenfield Hospital,

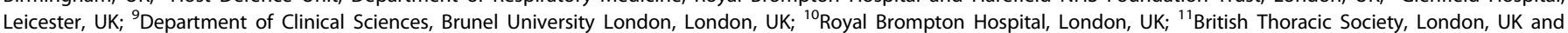
${ }^{12}$ Respiratory Medicine, Royal Infirmary of Edinburgh, and University of Edinburgh, Edinburgh, UK Correspondence: Kevin Gruffydd-Jones (gruffbox@btinternet.com)
}

Received: 18 February 2019 Accepted: 29 May 2019

Published online: 27 June 2019 
Table 1. SIGN levels of evidence $e^{5,6}$

Grade Evidence

$1++$ High-quality meta-analyses, systematic reviews of RCTs or RCTs with a very low risk of bias

$1+\quad$ Well-conducted meta-analyses, systematic reviews of RCTs or RCTS with a low risk of bias

1- Meta-analyses, systematic reviews of RCTs or RCTs with a high risk of bias

$2++$ High-quality systematic reviews of case-control or cohort studies or high-quality case-control or cohort studies with a very low risk of confounding, bias or chance and a high probability that the relationship is casual

2+ Well-conducted case-control or cohort studies with a low risk of confounding, bias or chance and a moderate probability that the relationship is casual

2- Case-control or cohort studies with a high risk of confounding, bias or chance and a significant risk that the relationship is not casual

3 Non-analytic studies, for example, case reports and case series

4 Expert opinion

$R C T$ randomised control trial

Table 2. SIGN grades of recommendation ${ }^{5,6}$

Grade Type of evidence

A At least one meta-analysis, systematic review or RCT rated as $1++$ and directly applicable to the target population or a systematic review of RCTs or a body of evidence consisting principally of studies rated as 1+ directly applicable to the target population and demonstrating overall consistency of the results

B A body of evidence, including studies rated as $2++$ directly applicable to the target population and demonstrating overall consistency of the results or extrapolated evidence from studies rated as $1++$ or $1+$

C A body of evidence, including studies rated as $2+$ directly applicable to the target population and demonstrating overall consistency of the results or extrapolated evidence from studies rated as $2++$

Evidence of level 3 or 4 or extrapolated evidence from studies rated as $2+$

Important practical points for which there is no research evidence, nor is there likely to be any research evidence. The guideline committee wishes to emphasise these good practice points

persistent cough, who also report difficult-to-treat asthma, ${ }^{9}$ rheumatoid arthritis, ${ }^{10}$ inflammatory bowel disease (IBD), ${ }^{11}$ chronic rhinosinusitis ${ }^{12}$ or the presence of persistent sputum pathogens, especially $P$. aeruginosa. ${ }^{1}$

\section{HISTORY, EXAMINATION AND INVESTIGATIONS}

If bronchiectasis is suspected in a patient in a primary care setting, a full medical history and examination should be first directed to exclude other causes of cough, such as COPD, lung cancer, asthma and gastro-oesophageal reflux. Persistent basal, coarse lung crackles may be present.

Investigations in the primary care setting should encompass:

- Diagnostic spirometry to look for other/coexistent diagnoses (such as COPD) and may be normal, restrictive or obstructive.

- Sputum microbiology is helpful in identifying the presence of persistent pathogens, especially $P$. aeruginosa (indicating a worse prognosis).

- A chest X-ray should be carried out to help exclude alternative diagnoses, but has limited sensitivity for diagnosing bronchiectasis, especially in mild disease.

- Definitive diagnosis of bronchiectasis is made, using thinsection CT scanning of the chest. It is highly accurate and diagnostic for bronchiectasis, with false-positive and falsenegative rates of $1 \%$ and $2 \%$, respectively..$^{13}$ Referral for CT will usually be made via a secondary care specialist, although some primary care practitioners may have direct access.

Figure 1 shows a suggested diagnostic algorithm by the authors of this article for patients suspected of having bronchiectasis in primary care.

\section{ASSESSMENT AND ROUTINE}

It is recommended that the initial assessment after diagnosis of bronchiectasis is carried out by a specialist respiratory team, where investigations can take place to elucidate any underlying cause and to formulate a treatment plan, which can be shared with the patient, primary care team and community team where appropriate. Single-centre studies suggest that investigations into the underlying cause of bronchiectasis can change management in $5-37 \%$ patients. $^{14}$

The underlying causes can include conditions such as allergic bronchopulmonary aspergillosis, immune deficiency, cystic fibrosis (in relevant patients) and non-tubeculous mycobacterial (NTM) disease. ${ }^{14,15}$ Co-morbid conditions should be assessed, including asthma, COPD, gastro-oesophageal reflux disease (GORD), rheumatoid arthritis and inflammatory bowel disease, and treated accordingly.

The treatment plan should give details of treatment in the stable condition, advice on treatment in the event of an acute exacerbation and arrangements for follow-up (primary care, hospital care and shared care). See Fig. 2 for a suggested checklist as part of the algorithm for review and management of patients wth bronchiectasis in primary care.

\section{ROUTINE REVIEW}

Patients at higher risk of future exacerbations should be reviewed in specialist care, where they present with or develop one or more of the following clinical situations: ${ }^{1}$

- They experience three or more exacerbations in 1 year.

- They have chronic Pseudomonas aeruginosa, non-tuberculous 
Adults with suspected bronchiectasis - primary care diagnosis

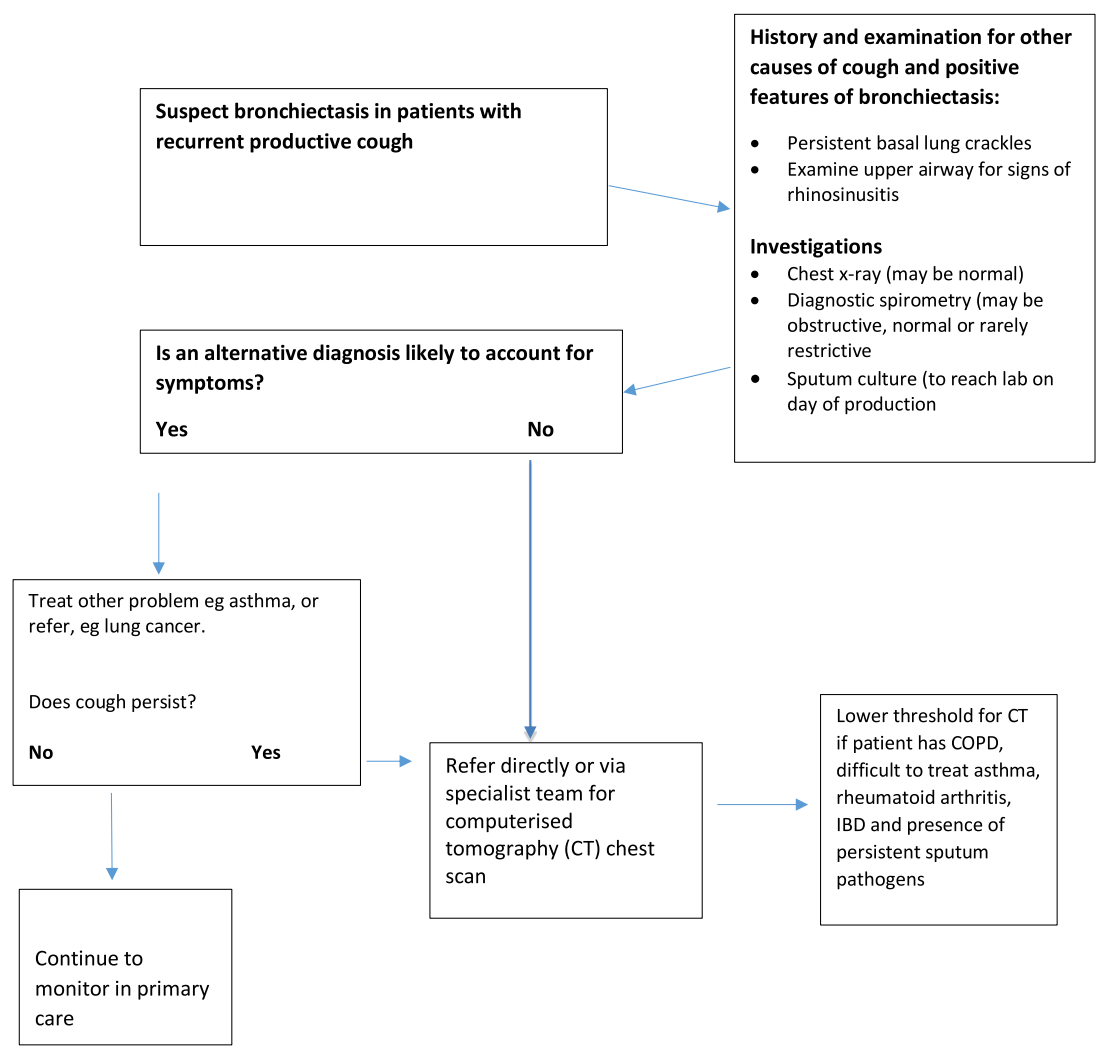

Fig. 1 Proposed algorithm for the diagnostic pathway in primary care of patients suspected of having bronchiectasis

mycobacteria (NTM) or methicillin-resistant Staphylococcus aureus (MRSA) colonisation.

- There is deteriorating bronchiectasis with declining lung function.

- They have associated rheumatoid arthritis, immune deficiency, inflammatory bowel disease or primary ciliary dyskinesia.

- They have allergic bronchopulmonary aspergillosis.

- Patients with advanced disease and those considering lung transplantation.

Lower-risk patients can be routinely reviewed in primary care. The exact frequency of review should be determined in the initial treatment plan, in consultation with the respiratory specialist and also by changing clinical conditions, but should be at a minimum frequency of once a year.

Factors to be routinely monitored by the primary care team (see Fig. 2) include:

- Assessment of symptoms (cough, sputum production and breathlessness) and their impact on daily activities.

- Chronic cough that can have a significant effect on daily activities, including sexual relations and urinary incontinence in women. ${ }^{16}$

- Exacerbation frequency.

- Body mass index (BMI).

- Pulse oximetry.

- Spirometry.

- The sputum should be sent for microbiological analysis when the patient is clinically stable, and should be sent at the start of an exacerbation before antibiotic treatment is started. ${ }^{1}$

- Compliance with sputum clearance exercises and shared treatment plan.
Deterioration in lung function, exacerbation frequency or clinical state should prompt specialist referral (see above). If the patient's BMI is $<20 \mathrm{~kg} / \mathrm{m}^{2}$, then specialist nutritional advice should be sought. In addition, the patient should be referred to a respiratory physiotherapist to reinforce the sputum clearance exercises if necessary. Similarly, referral for pulmonary rehabilitation should be considered, if the patient has functionally disabling breathlessness (MRC score $\geq 2$ ).

Common co-morbidities, such as mild-to-moderate asthma or COPD, can be treated in the primary care setting, according to national or international guidelines for these conditions. ${ }^{17-20}$ It is recommended that chronic rhinosinusitis be treated with nasal saline douching and intranasal steroids. There is a strong association between bronchiectasis and gastro-oesophageal disease (GORD) and patients with GORD have a more severe disease. $^{21}$ The guideline recommends that symptoms of GORD are specifically sought out and treated, according to the existing NICE guidance, but do not provide evidence that treatment of GORD will improve bronchiectasis outcomes.

\section{MANAGEMENT}

The overall aims of management are to prevent further damage (treat the underlying cause if possible), maximise function and quality of life and prevent and treat exacerbations. Figure 3 shows a stepwise approach to management. ${ }^{1}$

\section{PHYSIOTHERAPY}

All patients with bronchiectasis should be assessed by a respiratory physiotherapist. Chest physiotherapy can mobilise 
Primary care management of adults with bronchiectasis

\section{Initial Assessment}

To be carried out by specialist team and shared management plan formulated

\section{Checklist}

- Confirm diagnosis made by CT

- Underlying cause?

- Assessment of co-morbidities

- Baseline spirometry, oxygen sats

- Result of sputum bacteriology

- Pneumococcal vaccine (if not already given)

- Annual influenza vaccine

- Recommended pharmacotherapy

- Action plan for sputum clearance and/or pulmonary rehab

- Recommendations for acute exacerbation (discuss action plan)

- Check spirometry

- Document results of sputum culture

- Pulse oximetry

- Assess co-morbidities

- Influenza vaccine

- Record exacerbation history

- Check compliance with airway clearance techniques

- Review action plan

\begin{tabular}{l|l|l} 
Treatment of acute exacerbation & \\
Check oxygen sats, vital signs & $\begin{array}{l}\text { Review } \\
\text { Admit if respiratory distress/adverse } \\
\text { psychosocial factors }\end{array}$ \\
according to \\
clinical concern
\end{tabular}

If not admitted:

Obtain sputum sample

Treatment with antibiotics according

to previous sensitivities

Treat acute co-morbidities eg COPD

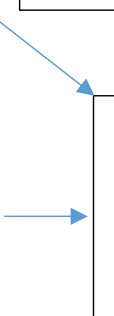

Refer to specialist team if: $\geq 3$ exacerbations/year Chronic colonisation with $P$. aeruginosa, MRSA or NTM Deteriorating bronchiectasis with declining lung function Patients with ABPA Patients receiving longterm antibiotic therapy (oral, inhaled, nebulised) Patients with associated $I B D$, rheumatoid arthritis, $P C D$, immune deficiency* Patients with advanced disease/ considering transplantation.

\footnotetext{
MRSA Methicillin-Resistant Staphylococcus aureus

NTM Non-tuberculous mycobacteria

IBD Inflammatory Bowel Disease

$P C D$ Primary Ciliary Dyskinesia

ABPA Allergic Bronchopulmonary Aspergilllosis
}

Fig. 2 Proposed algorithm for the review and management of patients with bronchiectasis in primary care

secretions and aid effective expectoration, ${ }^{2-24}$ providing improvement in cough scores. Table 3 shows the key elements of physiotherapy intervention.
INFLUENZA AND PNEUMOCOCCAL IMMUNISATION

It is important to offer annual influenza immunisation to all patients with bronchiectasis. ${ }^{25}$ In addition, the guidelines recom- 
Antibiotics are used to treat exacerbations that present with an acute deterioration (usually over several days) with worsening local symptoms (cough, increased sputum volume or change viscosity, increased sputum purulence with or without increasing wheeze, breathlessness, haemoptysis) and/or systemic upset.

The flow diagram refers to three or more annual exacerbations

\begin{tabular}{|c|c|}
\hline Step 1 & \\
\hline $\begin{array}{l}\text { - Treat underlying cause } \\
\text { - Airways clearance techniques } \\
+/ \text { - pulmonary rehabilitation } \\
\text { - Annual influenza vaccination } \\
\text { - Prompt antibiotic treatment } \\
\text { for exacerbations } \\
\text { - Self-management plan }\end{array}$ & $\begin{array}{l}\quad \text { Step } 2 \\
\quad \frac{\text { If } 3 \text { or more }}{\text { exacerbations/yr }} \\
\underline{\text { despite Step 1* }} \\
\text { - Physiotherapy } \\
\text { reassessment } \\
\text { and consider mucoactive } \\
\text { treatment }\end{array}$ \\
\hline
\end{tabular}

\begin{tabular}{|c|}
\hline $\begin{array}{c}\text { Step } 3 \\
\frac{\text { If } 3 \text { or more exacerbations/yr }}{\text { despite Step } 2^{*}}\end{array}$ \\
\hline $\begin{array}{l}\text { 1. If Pseudomonas } \\
\text { aeruginosa, long term inhaled } \\
\text { anti-pseudomonal antibiotic } \\
\text { or alternatively long term } \\
\text { macrolide }\end{array}$ \\
\hline $\begin{array}{l}\text { 2. If Other Potenitally P } \\
\text { Pathogenic Microorganisms, } \\
\text { long term macrolides or } \\
\text { alternatively long term oral } \\
\text { or inhaled targeted antibiotic }\end{array}$ \\
\hline $\begin{array}{l}\text { 3. If no pathogen, long term } \\
\text { macrolide }\end{array}$ \\
\hline
\end{tabular}

\begin{tabular}{|c|}
\hline $\begin{array}{c}\text { Step } 4 \\
\frac{\text { If } 3 \text { or more }}{\text { exacerbations/yr }} \\
\frac{\text { despite Step } 3^{*}}{\text { - Long term macrolide }} \\
\text { and long term inhaled } \\
\text { antibiotic }\end{array}$ \\
\end{tabular}

\begin{tabular}{|c|}
\hline \multicolumn{1}{|c|}{ Step 5 } \\
$\frac{\text { If } 5 \text { more }}{\text { exacerbations/yr }}$ \\
$\frac{\text { despite Step 4* }}{\text { - Consider regular }}$ \\
intravenous antibiotics \\
every 2-3 months
\end{tabular}

\footnotetext{
* Consider this step if significant symptoms persist despite previous step,
}

even if not meeting exacerbation criteria

Fig. 3 Stepwise management of patients with bronchiectasis. Reproduced from ref. ${ }^{1}$, with permission from BMJ Publishing Group Ltd.

Table 3. Key elements of physiotherapy in bronchiectasis

- Patients are taught to carry out airway clearance techniques, such as active cycle of breathing technique (ACBT) ${ }^{15}$ (or using an oscillating positive expiratory pressure device, such as the "Flutter" and "Acapella". ${ }^{16}$ This is tailored to the individual patient (usually once to twice daily) and may be increased during an exacerbation.

- Airway clearance may be optimised using postural drainage (use of gravity-assisted positioning to drain areas of the lung) and prior inhalation of isotonic or hypertonic saline.

- Consider a 6-month trial of mucolytic agents (such as oral carbocisteine) if there are continued difficulties with sputum expectoration.

- Pulmonary rehabilitation should be offered where a patient is functionally limited by breathlessness (MRC score $\geq 2$ ). ${ }^{16}$

mend that polysaccharide pneumococcal vaccination should be offered to all patients with bronchiectasis (if not previously given), although this recommendation comes from evidence that 23 valent pneumococcal vaccinations can reduce the risk of all-cause pneumonia. $^{26}$

\section{INHALED CORTICOSTEROIDS AND BRONCHODILATORS}

Treatment with inhaled corticosteroids (ICS) in bronchiectasis is not recommended, unless the drug is needed for comorbid diseases, such as asthma or COPD, according to treatment guidelines. ${ }^{17-20}$ A Cochrane review showed that treatment with ICS demonstrated a minimal reduction in sputum volume, but no effect on exacerbations. ${ }^{27}$ The studies included in the article used a relatively high dose of ICS ( $\geq 800 \mathrm{mcg}$ of beclometasone equivalent) and there was a high incidence of local and systemic side effects. It is recommended to offer a trial of long-acting inhaled bronchodilators in patients with significant breathlessness or where there is coexistent asthma and/or COPD. ${ }^{1}$

No evidence was found for the use of short-acting beta- 2 agonists and limited evidence for long-acting beta- 2 agonists (LABA) and long-acting anti-muscarinic agents (LAMA). ${ }^{28}$ Use of LABA and LAMA is recommended in patients with significant breathlessness and coexistent obstructive airway disease of whatever aetiology.

\section{LONG-TERM ANTIBIOTIC THERAPY}

Long-term-3 months or more-antibiotic therapy should be considered for patients with three or more exacerbations per year, which should be initiated and monitored by specialist teams in secondary care. Treatment with oral azithromycin, $250 \mathrm{mg}$, three times weekly for a year can reduce the incidence of exacerbations in patients with bronchiectasis, ${ }^{29}$ and this is recommended as a pragmatic starting dose in the guidelines. ${ }^{1}$ In patients with concurrent $P$. aeruginosa infection, the recommended first-line therapy is inhaled colistin. Sputum samples from a secondary care population show that $H$. influenzae and $P$. aeruginosa are the most common bacterial isolates with other pathogens, such as $M$. catarrhalis, S. pneumoniae and non-tuberculous mycobacteria also being found. ${ }^{30}$ The presence of $P$. aeruginosa not only guides the choice of antibiotic therapy, but also signifies a worse prognosis with a threefold risk in mortality, higher risk of hospital admission and poorer quality of life. ${ }^{31}$

\section{MANAGEMENT OF THE ACUTE EXACERBATION}

Where an acute exacerbation incident is suspected, the first step should be to assess the vital signs (pulse oximetry, pulse rate, respiratory rate, temperature and blood pressure). In the primary care setting, the patient should be treated for acute comorbidities, such as asthma and COPD, according to diseasespecific guidelines. ${ }^{17-20,32}$ The patient should be considered for admission to a secondary care setting, where there are features of sepsis or respiratory distress, where there are significant co- 
K. Gruffydd-Jones et al.

Table 4. Common organisms associated with acute exacerbations of bronchiectasis and suggested oral antibiotics ${ }^{1}$

\begin{tabular}{|c|c|c|c|c|}
\hline Organism & Recommended first-line treatment & $\begin{array}{l}\text { Length of } \\
\text { treatment }\end{array}$ & Recommended second-line treatment & $\begin{array}{l}\text { Length of } \\
\text { treatment }\end{array}$ \\
\hline $\begin{array}{l}\text { Streptococcus } \\
\text { pneumoniae }\end{array}$ & Amoxicillin $500 \mathrm{mg}$ tds & 14 days & Doxycycline $100 \mathrm{mg} \mathrm{BD}$ & 14 days \\
\hline $\begin{array}{l}\text { H. influenzae-beta } \\
\text { lactamase negative }\end{array}$ & $\begin{array}{l}\text { Amoxicillin } 500 \mathrm{mg} \text { tds or amoxicillin } \\
1 \mathrm{G} \text { tds or amoxicillin } 3 \mathrm{G} B D\end{array}$ & 14 days & $\begin{array}{l}\text { Doxycycline } 100 \mathrm{mg} \text { BD or ciprofloxacin } 500 \text { or } 750 \mathrm{mg} \\
\text { BD or ceftriaxone } 2 \mathrm{G} \text { OD (IV) }\end{array}$ & 14 days \\
\hline $\begin{array}{l}\text { H. influenzae-beta } \\
\text { lactamase pos }\end{array}$ & $\begin{array}{l}\text { Amoxicillin with clavulanic acid } 625 \\
\text { one tablet tds }\end{array}$ & 14 days & $\begin{array}{l}\text { Doxycycline } 100 \mathrm{mg} \text { BD or ciprofloxacin } 500 \text { or } 750 \mathrm{mg} \\
\text { BD or ceftriaxone } 2 \mathrm{G} \text { OD (IV) }\end{array}$ & 14 days \\
\hline $\begin{array}{l}\text { Staphylococcus aureus } \\
\text { (methicillin sensitive) }\end{array}$ & Flucloxacillin $500 \mathrm{mg}$ qds & 14 days & $\begin{array}{l}\text { Clarithromycin } 500 \mathrm{mg} \mathrm{BD} \text { or doxycycline } 100 \mathrm{mg} \text { BD or } \\
\text { amoxicillin with clavulanic acid } 625 \text { one tablet tds }\end{array}$ & 14 days \\
\hline $\begin{array}{l}\text { Pseudomonas } \\
\text { aeruginosa }\end{array}$ & $\begin{array}{l}\text { Oral ciprofloxacin } 500 \mathrm{mg} \mathrm{BD}(750 \mathrm{mg} \\
\text { BD in more severe infection) }\end{array}$ & 14 days & Discuss with a respiratory specialist/microbiologist & \\
\hline
\end{tabular}

morbidities and/or psychosocial factors or there is a need for intravenous antibiotics, where a community service to provide these is not available.

\section{ACUTE ANTIBIOTIC THERAPY}

Where possible, the sputum should be obtained for culture and sensitivity testing prior to commencing antibiotics. However, empirical antibiotics can be started whilst awaiting the sputum results. Table 4 shows common organisms associated with acute exacerbations of bronchiectasis and their treatment in primary care. In general, antibiotic courses for 14 days are standard and should always be used in patients infected with $P$. aeruginosa. Shorter courses may suffice in patients with mild bronchiectasis (usually 7-10 days). It is recommended to consider providing a home sputum pot and standby antibiotics for future exacerbations.

\section{PROGNOSIS}

Patients with mild bronchiectasis should have a normal life expectancy, but in patients with more-advanced bronchiectasis, there is an increased risk of recurrent exacerbations, vascular disease and mortality. ${ }^{30,31,33}$

\section{CONCLUSIONS}

A diagnosis of bronchiectasis should be suspected when a patient presents with a persistent or recurrent productive cough. Definitive diagnosis is made by thin-section CT scan of the chest. Assessment of bronchiectasis should be carried out in secondary/tertiary care, where a shared management plan should be formulated with the patient and the community/primary care team.

Many patients can be routinely managed in primary care, where the cornerstone of management is physiotherapy to improve sputum clearance and maximise exercise capacity and prompt treatment of exacerbations with antibiotics.

The British Thoracic Society Bronchiectasis Guidelines provide advice for diagnosis and management of primary care in the United Kingdom. Although some of the advice, such as the type of antibiotics to be used, is specific to the United Kingdom, many of the recommendations are in line with those of the European Respiratory Society Guidelines $2017,{ }^{34}$ and provide a sound basis for primary care management of this increasingly prevalent disease throughout the world.

\section{DATA AVAILABILITY}

This article draws on the BTS Guideline for Bronchiectasis in Adults-evidence tables supporting the guideline are available on the BTS website: https://www.brit-thoracic. org.uk/quality-improvement/guidelines/bronchiectasis-in-adults/.

\section{ACKNOWLEDGEMENTS}

The support of the British Thoracic Society and the Primary Care Respiratory Society in the development of this article is acknowledged. The BTS Guideline for Bronchiectasis in Adults was funded by the British Thoracic Society-no external funding.

\section{AUTHOR CONTRIBUTIONS}

K.G.J. was the lead author and member of the Guideline group and led the drafting and revision of the paper. A.T.H., A.L.S. and M.R.L. chaired the guideline group. All authors undertook revisions of the paper. K.G.J. and A.T.H. had final responsibility for the paper, which was approved by all authors.

\section{ADDITIONAL INFORMATION}

Competing interests: K.G.J. has declared funding from Boehringer Ingelheim, GlaxoSmithkline, Astra Zeneca, Napp, TEVA, Chiesi, Nutricia and Novartis. M.R.L. has declared funding from Astra Zeneca, Bayer Healthcare, Insmed, Pulmocide, Griffols, Polyphor and Savara. V.K. has declared funding for educational sessions from Astra Zeneca, Napp, Chiesi, Pfizer, Boehringer Ingelheim, TEVA and GSK. A.T.H., D.K., A.L.S., K.P., A.H., L.G., X.R., A.W. and S.A.W. declare no competing interests.

Publisher's note: Springer Nature remains neutral with regard to jurisdictional claims in published maps and institutional affiliations.

\section{REFERENCES}

1. Hill, A. T. et al. British Thoracic Guideline for bronchiectasis in adults. Thorax. $\mathbf{7 4}$ (Suppl 1), 1-69 (2019).

2. Quint, J. K. et al. Changes in the incidence, prevalence and mortality of bronchiectasis in the UK from 2004 to 2013: a population-based cohort study. Eur. Respir. J. 47, 186-193 (2016).

3. Weycker, D. et al. Prevalence and incidence of noncystic fibrosis bronchiectasis among US adults. 2013 Chronic Respir. Dis. 14, 377-384 (2013).

4. Pasteur, M. C. et al. British Thoracic Society Guidelines for non-cystic fibrosis bronchiectasis. Thorax. 65(Suppl 1), i1-i58 (2010).

5. British Thoracic Society Standards of Care Committee Guideline Production Manual 2016. www.brit-thoracic.org.uk (2016).

6. Scottish Intercollegiate Guidelines Network (SIGN). SIGN 50: a Guideline Developer's Handbook. (SIGN: Edinburgh, 2003).

7. Ni, Y. et al. Clinical characteristics of patients with chronic obstructive pulmonary disease and bronchiectasis: a systematic review and meta-analysis. Int J. Chron. Pulmon Dis. 10, 1465-1475 (2015). 
8. O'Brien, C. et al. Physiological and radiological characterisation of patients diagnosed with chronic obstructive pulmonary disease in primary care. Thorax. 55, 635-642 (2000)

9. Gupta, S. et al. Qualitative analysis of high-resolution CT scans in severe asthma. Chest 136, 1521-1528 (2009).

10. Allain, J. et al. Prevalence of symptomatic bronchiectasis in patients with rheumatoid arthritis. Rev. Rheum. Eng. Ed. 64, 531-537 (1997).

11. Black, H., Mendoza, M. \& Murin, S. Thoracic manifestations of inflammatory Bowel disease. Chest 131, 524-532 (2007).

12. Shoemark, A., Ozerovitch, L. \& Wilson, R. Aetiology in adult patients with bronchiectasis. Respir. Med. 101, 1163-1170 (2007).

13. Young, K. A. \& Kolbenstvedt, A. High resolution CT and bronchography in the assessment of bronchiectasis. Acta Radiol. 32, 439-441 (1991).

14. Pasteur, M. C. et al. An investigation into causative factors in patients with bronchiectasis. Am. J. Respir. Crit. Care Med. 162(4 Pt 1), 1277-1284 (2000).

15. Lonni, S. et al. Etiology of non-cystic fibrosis bronchiectasis in adults and it's correlation to disease severity. Ann. Am. Thorac. Soc. 2, 1764-1770 (2015).

16. Rees, J. T. et al. Managing urinary incontinence in adults with bronchiectasis. Br. J. Nurs. 22, S15-S16 (2013). S18.

17. BTS/SIGN Guideline for the management of asthma. www.brit-thoracic.org.uk standards-of-care/guidelines/btssign-british-guideline-on-the-management-ofasthma (2016).

18. National Institute of Health and Care Excellence (NICE) Guideline NG115 December 2018: Chronic Obstructive Pulmonary disease in over 16's. Diagnosis and management. www.nice.org.uk/guidance/ng115 (2018).

19. Global Initiative for Chronic Lung Disease (GOLD) Global Strategy for Diagnosis, Management and Prevention of Chronic Obstructive Obstructive Disease. www. goldcopd.org (2019).

20. Global Initiative for Asthma (GINA). Global strategy for asthma management and prevention. www.ginasthma.org (2018).

21. Mandal, P. et al. Symptoms of airway reflux predict exacerbations an quality of life in bronchiectais. Respir. Med. 107, 1008-1013 (2013).

22. Murray, M. P. et al. A randomised crossover trial of chest physiotherapy in noncystic fibrosis bronchiectasis. Eur. Respir. J. 34, 1086-1092 (2009).

23. O'Neill, B. et al. current physiotherapy management of patients with bronchiectasis: a UK survey. Int J. Clin. Pract. 56, 34-35 (2002).

24. Lee, A. L. et al. The short and long term effects of exercise training in noncystic fibrosis bronchiectasis; a randomized controlled trial. Respir. Res. 15, 44 (2014).
25. Poole, P. J. et al. Influenza vaccine for patients with chronic obstructive pulmonary disease. Cochrane Database Syst. Rev. 2006, CD002733 (2006).

26. Moberley, S. et al. Vaccines for preventing pneumococcal infection in adults Cochrane Database Syst. Rev. 213, CD000422 (2013).

27. Kapur, N. et al. Inhaled steroids for bronchiectasis. Cochrane Database Syst. Rev. 86, CD000996 (2009).

28. Nogrady, S. et al. Reversibility of airways obstruction in bronchiectasis. Thorax. 33, 635-637 (1978).

29. Altenburg, J. et al. Effect of azithromycin maintenance treatment on infectious exacerbations among patients with non-cystic fibrosis bronchiectasis: the BAT randomized controlled trial. JAMA 309, 1251-1259 (2013).

30. Kelly, M. G., Murphy, S. \& Elborn, J. S. Bronchiectasis in secondary care: a comprehensive profile of a neglected disease. Eur. J. Intern Med. 2003 14, 488-492 (2003).

31. Goeminne, P. C. et al. Mortality in non-cystic fibrosis bronchiectasis: a prospective cohort analysis. Respir. Med. 108, 287-296 (2014).

32. British Thoracic Society Guidelines for management of community acquired pneumonia. www.brit-thoracic.org.uk/document-library/clinical-information/ pneumonia/adult-pneumonia/a-quick-reference-guide-bts-guidelines-for-themanagement-of-community-acquired-pneumonia-in-adults (2009).

33. Ellis, D. A. et al. Present outlook in bronchiectasis: clinical and social study and review of factors influencing prognosis. Thorax. 36, 659-664 (1981).

34. Polverino, E. et al. European Respiratory Society guidelines for the management of adult bronchiectasis. Eur. Respir. J. 50, 1700629 (2017)

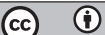

Open Access This article is licensed under a Creative Commons Attribution 4.0 International License, which permits use, sharing, adaptation, distribution and reproduction in any medium or format, as long as you give appropriate credit to the original author(s) and the source, provide a link to the Creative Commons license, and indicate if changes were made. The images or other third party material in this article are included in the article's Creative Commons license, unless indicated otherwise in a credit line to the material. If material is not included in the article's Creative Commons license and your intended use is not permitted by statutory regulation or exceeds the permitted use, you will need to obtain permission directly from the copyright holder. To view a copy of this license, visit http://creativecommons. org/licenses/by/4.0/.

(c) The Author(s) 2019 